\title{
The Perception of Japanese Cars by Market: Saudi Arabia and The United States and The Value Versus Price Proposition
}

\author{
Fadye Saud AlFayad \\ Management and information Technology Department, \\ Jubail Industrial College \\ P.O. Box 10099 Jubail Industrial City 31962, Saudi Arabia
}

\begin{abstract}
This study has worked to explore the characteristics of the Saudi Arabia new car market in comparison to certain aspects of the United States new car market. Specifically, this study sought to identify the unique perspectives that Saudi new car consumers have towards Japanese produced new cars compared to those of US new car consumers towards Japanese produced vehicles. Furthermore, the added element of identifying whether one market privileged value above price or price above value as a rationale in making a purchase decision was also examined. A quantitative methodology was utilized in approaching this research problem. The specific quantitative method selected was descriptive statistics because of its ability to isolate unique attributes in the data and to support conclusions about those attributes by quantifying consumer opinion in one respect or another. This study found that Saudi new car consumers in fact do have a positive perception of Asian and specifically Japanese produced cars. This assertion is supported both through the data and the fact that a Japanese car is currently the top selling new car sold in the Kingdom. Additionally, the data also finds that Saudi new car consumers tend to privilege the consideration of overall value as defined by efficiency, quality and price as a rationale to arrive at a purchase decision. Likewise, this study finds that the US new car consumer, while operating in a much different new car marketplace, tends to privilege price rather than value in the arrival at a purchase decision. Finally, this study also notes that the recent approval of women being able to drive in the Kingdom is a manifestation of the success of the Crown Prince's Vision 2030 program. This development is indicative of the way in which the Vision 2030 objectives are remaking the Saudi economy, evidenced by the new car market, into a rich consumer-driven ecosystem capable of establishing the Kingdom as an international economic benchmark.
\end{abstract}

\section{INTRODUCTION AND OVERVIEW}

The study examines the unique perceptions of Asian produced cars in the Saudi Arabian (SA) market versus the United States (US) market. Specifically, the way that factors such as perceived value compared to the importance of price proposition are examined as a means to understand exactly how Japanese cars are viewed by Saudi consumers. The fact that the origin of a vehicle brand such as Japan can affect value and price perceptions is understood to some degree as a function of product segmentation: “...heterogeneity among brand origins determines different prices...the structure of brand origin heterogeneity and its respective effect on prices varies across different car-type segments" (Saridakis \& Baltas, 2016, p.78). Thus, there is an understanding that just because a vehicle originates from Japan as the origin of manufacture, it is expected to be accompanied with certain product attributes or qualities based on this origin.

Yet, isolating how these expectations or assumptions manifest themselves differently across different markets is beneficial to developing a better understanding of the Saudi car market. Therefore, this study examines the unique perceptions of the Saudi automotive market 
regarding Japanese cars as well as those found within the US market towards Japanese produced cars. This analysis of these factors involving value versus price propositions are undertaken through the application of statistical analysis tools and specifically descriptive statistics. This type of statistical analysis has been utilized in other studies involving Asian produced passenger vehicles with some success.

For the analysis of new car purchase patterns, it is important to be able to descriptively frame both purchase rationale and preferences by market. For instance, authors Uma and Ramanathan applied descriptive statistics to the question of what selling propositions vehicle consumers perceived in relation to Suzuki, Hyundai and Renault passenger vehicles as a precursor to switching from scooters to cars (2016). Consequently, descriptive statistics promotes the capacity of the researcher to identify important relationships in the data and how certain product factors like value versus price inter-relate. In terms of this study, SA based consumers were asked to respond to a series of questions regarding Japanese versus other car brands as seen in the following table:

Table 1: Study Questions and Overall Results

\begin{tabular}{|l|cccc|}
\hline \hline & Minimums & Maximums & $\begin{array}{c}\text { Std. } \\
\text { Mean }\end{array}$ & \begin{tabular}{c} 
Deviation \\
\hline Respondent Age
\end{tabular} \\
Gender of Respondents & 18 & 65 & 32,92 & 13,702 \\
Normalization Scale & 0 & 1 &, 56 &, 499 \\
Manufacture Origin Importance & 1,67 & 4,67 & 3,170 &, 70626 \\
Selecting a Japanese Car & 0 & 5 & 3,34 & 1,363 \\
Selecting a Non-Japanese Car & 0 & 1 &, 23 &, 424 \\
Preference of Value & 0 & 1 &, 44 &, 498 \\
Preference of Price & 0 & 1 &, 33 &, 471 \\
\hline \hline
\end{tabular}

Likewise, US new car consumers were also asked about their new car preferences vis-à-vis their markets of origin. However, unlike SA new car consumers, US new car consumers, who have far more choices and a much longer history of new car selection habits, were asked to frame this preference in relation to US produced vehicles versus non-US produced vehicles. The results of these inquiries will reveal the interaction between these two critical factors of value versus price in the selection of a new vehicle. The data collection tools can be found in appendix 1 in the Appendices section of this report.

\section{SAUDI MARKET PERCEPTIONS}

The SA car market is increasingly one of the most important new car markets globally. This is because SA is a central pillar in the Middle East economy and the volume of new vehicle sales in the Kingdom affects the regional economy in a variety of ways. Presently, estimates indicate that at least 600 thousand new vehicles are achieved annually with the expectation that this figure will increase by 300 thousand or more once women are fully integrated into the new car marketplace (Financing, 2017). These new car sales figures are expected to increase dramatically as Saudi women start to drive, purchase their own vehicles and begin to express their own unique new car preferences in the marketplace. Obviously, increasing the number of new car sales in the Kingdom by $50 \%$ will have enormous implications for the national economy. These include positive effects on overall gross domestic product (GDP), worker productivity measures and downstream effects such as import taxes, custom duties and ancillary industries. 
However, some of the promised gains in the value and size of the new car market in SA will be offset by recent changes to the nation's tax structure. The Kingdom recently introduced a new value added tax or VAT which adds $5 \%$ tax to new vehicle sales in the Kingdom. This is a significant tax burden on a market that is already taxed fairly high and that is subject to enormous volatility because of its dependence on the petroleum industry. Some estimates indicate that new car sales may be down 24\% during the 1st quarter of 2018 although major Japanese brands such as Toyota have retained their respective market shares such as Toyota's stable 31\% market share (Saudi, 2018). While it is the Toyota brand that seems to dominate in the Saudi marketplace, the luster of the Toyota brand transfers to other Japanese brands. This is a process referred to as haloing in which the success of one product, category or brand elevates the impression of others that are related to them in some fashion (Borah \& Tellis, 2016). Regardless, it is this substantial market share of Japanese cars in the Saudi market than indicates just how Japanese cars are perceived in the SA market. Toyota manages to maintain this market share for several reasons which apply to all the Japanese manufacturers. Basically, Japanese manufacturers offer new car products that run the segmentation gamut from introductory vehicle to high-end, luxury vehicles. For example, Mazda offers its introductory Mazda 6 in the Kingdom for approximately Riyal 100,500 while Toyota's Lexus division offers its LS for some Riyal 774,000 at the upper end of the spectrum resulting in about 300 thousand new car sales for Toyota alone (New, 2018). In fact, the Toyota Hilux is the best selling new car in SA and by itself outperforms many other brands in the Kingdom.

One of the most critical elements of the SA new car market in SA has been the recent approval of women being able to drive their own cars. The fact remains that women make up an enormous untapped new car consumer market in the Kingdom and there is little doubt that their influence on how new cars are perceived relative to value versus price is going to be important. The approval of driving for women is a cornerstone policy of Crown Prince Mohammed's Vision 2030 program. This program has focused on integrating SA's women into the national economy. The conclusion is that this is a sizeable market estimated to be some $43 \%$ of SA's approximate total of 31.5 million people and with the passage of this law in June of 2018, more than 165 thousand women recently signed up for SA's first driving school program (Omran \& Campbell, 2018). The fact that so many women signed up in advance of the law's passage for their driving privileges is indicative of enormous pent up demand in the new car marketplace in SA. Furthermore, it also just as certain that many if not most of these new women drivers are going to prefer, now or in the future, their own cars that reflect their own unique tastes, preferences and needs. Clearly, the influence of this particular market segment is going to be a pervasive one on the perception of Japanese cars.

In terms of the actual influence then on vehicle/brand preference based on origin, the data is fairly conclusive it would seem. It is understood that the most dominant new car market in the world is the US market. American new car brands tend to carry enormous influence across global markets even when their new vehicle products are not widely sold in a given market. The study's respondents, who provided the data anonymously after self-selecting to complete the survey in an online forum, took two surveys in which one included US new vehicle references and one did not. The data results reveal that Japanese cars are, by far, the preferred brand among SA new vehicle consumers: 
Table 2: Single Sample with US Vehicles

\begin{tabular}{|l|r|r|r|c|}
\hline & Null & $\begin{array}{c}\text { Mean of } \\
\text { the Data }\end{array}$ & Std. Deviation & $\begin{array}{c}\text { Mean of the } \\
\text { Error }\end{array}$ \\
\hline PREF_ORIG & 72 &, 74 &, 444 &, 052 \\
PREF_JAPN & 72 &, 04 &, 201 &, 024 \\
PREF US & 72 &, 03 &, 165 &, 020 \\
PREF_VALU & 72 &, 03 &, 165 &, 020 \\
PREF_PRIC & 72 &, 00 &, $000 a$ &, 000 \\
PREF DONC & 72 &, 07 &, 256 &, 030 \\
\hline
\end{tabular}

This table indicates that SA new vehicle consumers, by a 2-1 ratio, prefer Japanese brands. Additionally, while a larger percentage of the respondents stated that they did not care than the other categories except market of origin preferences, it is just as certain that brand features are a consideration.

Table 3: Single Sample Minus US Vehicles

\begin{tabular}{|c|c|c|c|c|c|c|}
\hline & \multicolumn{6}{|c|}{ Value of the Test $=0.17$} \\
\hline & & & & & $\begin{array}{r}95 \% \text { Co } \\
\text { Over }\end{array}$ & $\begin{array}{l}\text { Interval in } \\
\text { rence }\end{array}$ \\
\hline & $\mathbf{t}$ & df & Sig. (2-tailed) & $\begin{array}{c}\text { Mean } \\
\text { Difference }\end{array}$ & Lower & Upper \\
\hline PREF_ORIG & 10,823 & 71 & ,000 & ,566 & ,46 & 67 \\
\hline PREF_JAPN & $-5,411$ & 71 & 000 &,- 142 &,- 18 &,- 08 \\
\hline PREF_NONJ & $-7,292$ & 71 & ,000 &,- 128 &,- 18 &,- 10 \\
\hline PREF_VALU & $-7,292$ & 71 & ,000 &,- 126 &,- 18 &,- 10 \\
\hline PREF_DONC & $-3,333$ & 71 & 001 &,- 101 &,- 16 &,- 04 \\
\hline
\end{tabular}

In this test too, the importance of where a new vehicle is manufactured clearly makes a difference in a new vehicle selection. SA consumers consider where a new car is made to be of extreme importance. The data indicates that even when US vehicles are not included, Japanese vehicles remain the vehicle of choice for SA consumers.

\section{US MARKET PERCEPTIONS}

The US new car market is arguably the single most important new car market in the world. The number of brands available and the number of sales achieved annually is remarkable and forms a major segment of the national GDP in the market. The most recent figures indicate that more than 13 million unique units were sold annually over the prior 12 month period with some 415 passenger moving new vehicles sold per 1000 citizens in the US (U.S., 2018). These are quite remarkable figures and reveal just how intrinsically dependent the US economy is on the new vehicle market as a whole. Of course many of the new vehicle segments in the US are the same as those within the SA market. However, the US has certain segment-based idiosyncrasies that make it unique among global new vehicle markets. The following table demonstrates how US new vehicle segmentation is comprised based on new vehicle types: 
Table 4: New Vehicle Segmentation in the US

\begin{tabular}{|l|c|c|c|c|c|}
\hline & $\begin{array}{c}\text { 1st Quarter } \\
\text { Sales }\end{array}$ & $\begin{array}{c}\text { Change by } \\
\text { Percentage }\end{array}$ & \multicolumn{2}{|c|}{ Year-to-Date } & \multicolumn{2}{|c|}{ Cherall Amount of } \\
\hline Passenger Cars & 555,625 & -9.2 & $1,374,507$ & -10.8 & -14.5 \\
\hline Midsize & 231,529 & -13.4 & 580,263 & -10.8 & \\
\hline Small & 238,056 & -7.7 & 579,198 & & 0.7 \\
\hline Luxury & 86,029 & -0.9 & 215,006 & -64.0 & \\
\hline Large & 11 & -57.7 & 40 & & 9.8 \\
\hline Pickup Trucks & $1,097,904$ & 16.3 & $2,736,038$ & & 2.8 \\
\hline Pickups & 260,949 & 7.9 & 653,891 & & 18.2 \\
\hline Cross-overs & 572,829 & 27.0 & $1,415,954$ & & 2.7 \\
\hline Minivans & 48,325 & 5.2 & 126,145 & & 13.7 \\
\hline $\begin{array}{l}\text { Total SUV/Cross-over } \\
\text { Vehicles }\end{array}$ & 746,837 & 21.6 & $1,852,541$ & & 1.2 \\
\hline Total SUVs Sold & 174,008 & 6.6 & 436,587 & & 18.2 \\
\hline Total Cross-overs Sold & 572,829 & 27.0 & $1,415,954$ & & \\
\hline
\end{tabular}

(Auto, 2018)

It should be noted that passenger cars in the US new car market are actually experiencing a downward trend through the 1st quarter of 2018 and this trend appears to be sustained. The assumption is such that inflationary pressure on the price of these cars is exerting upward pressure on vehicle price and that this upward pressure on new car price is not offset by product traits, attributes or qualities. The data presented in the table above is fairly conclusive regarding the types of vehicles that new vehicle consumers prefer in the US.

Far and away, the most preferred new vehicle platform in the US is the pickup truck segment as the data in the previous table clearly demonstrates. Pickup trucks outsell passenger vehicles more than 2-1 and it is apparent that Japanese new vehicles primarily compete in the passenger car segments. As mentioned in previous comments, passenger car segments in the US new car market are actually trending downward but this trend does not seem to be affecting Japanese cars in the US new car marketplace. Thus, Japanese made vehicles do populate the top 10 list of most widely sold new vehicle platforms in the US market. The table below demonstrates that although Toyota is not in the top 3 most widely sold new vehicles in the US, another Japanese manufacturer actually is: 
Table 5: Most Popular Vehicles in the US Market

\begin{tabular}{|l|c|c|c|c|c|}
\hline & $\begin{array}{c}\text { 1st Quarter } \\
\text { Sales }\end{array}$ & $\begin{array}{c}\text { Change by } \\
\text { Percentage }\end{array}$ & $\begin{array}{c}\text { Year-to- } \\
\text { Date }\end{array}$ & \multicolumn{2}{c|}{$\begin{array}{c}\text { Overall Amount of } \\
\text { Change }\end{array}$} \\
\hline Ford F - Series PU & 87,011 & 7.0 & 214,191 & & 4.3 \\
\hline Chevrolet Silverado PU & 52,547 & 23.9 & 135,545 & & 5.5 \\
\hline Nissan Rogue & 42,151 & 6.7 & 116,454 & & 14.8 \\
\hline Dodge Ram PU & 41,307 & -10.9 & 103,964 & -12.8 & \\
\hline Toyota Camry & 35,264 & -1.1 & 90,767 & & 8.8 \\
\hline Toyota RAV4 & 34,937 & 9.1 & 91,461 & & 13.6 \\
\hline Honda Civic & 32,584 & 3.4 & 82,149 & & 0.6 \\
\hline Chevrolet Equinox & 31,940 & 40.9 & 82,398 & & 31.4 \\
\hline Honda CR-V & 31,868 & -3.1 & 82,046 & -12.8 & \\
\hline Toyota Corolla / Matrix & 29,245 & -4.4 & 72,791 & -4.3 & \\
\hline
\end{tabular}

(Auto, 2018)

Although Toyota, in this instance, has 3 new vehicle platforms in the top 10 most popular new vehicles sold in the US market, it does not have a vehicle in the top 3 even. Furthermore, Toyota is outsold in terms of top 10 vehicles by another Japanese manufacturer, Nissan and its Rogue platform which is the top 3 vehicle currently sold in the US market.

While it is apparent that American new car consumers have a preference for pickups in terms of segment choice, when it comes to passenger cars, they prefer Japanese vehicles. Much of this preference for Japanese vehicles relates to perceived assumptions regarding quality. For instance, one study confirms that US consumers consider Japanese cars to be more reliable, to be in better condition when delivered new and to have fewer engine or electrical problems over the life of the vehicle than other major manufacturers domestic or foreign (TuttleHollingsworth, 2015). Hence, the presence of a Japanese made new vehicle in the top 3 vehicles sold in the US is not surprising and Toyota's ability to have 3 different vehicles in the top 10 vehicles sold in the US is even more understandable. The survey data is presented in the table that follows:

Table 6: New Car Consumer Preferences in the US

\begin{tabular}{|l|c|c|c|c|}
\hline & Null & Mean & $\begin{array}{c}\text { Standard } \\
\text { Deviation }\end{array}$ & $\begin{array}{c}\text { Mean of the } \\
\text { Error }\end{array}$ \\
\hline PREF_US & 44 &, 70 &, 462 &, 070 \\
PREF JAPN & 44 &, 30 &, 462 &, 070 \\
\hline
\end{tabular}

As is apparent, the average respondent in the US market prefers US based vehicles by more than 21 but this data is skewed by product category apparent in the pickup sales information. If one removes the new pickup sales from the equation, Japanese cars not only outsell US made new vehicles but they would also have some 6 different vehicle platforms in the top 10 list of top selling new vehicles sold in the US market. Numbers like this are extremely telling given the inherent dependence that the US market has on new vehicle sales both from an economic perspective as well as a cultural perspective. 


\section{ANALYSIS AND DISCUSSION}

Ultimately, this study was able to collect 157 total responses from self-selecting participants. Of these 157 total responses, some were rejected for a variety of reasons such as being incompletely filled out, visibly inaccurate or incorrect responses and/or seemingly biased in character. Likewise, some 44 of the final study participants were of US origin while the remaining 72 of these study participants identified as being from SA. The data relating to the SA new car market revealed some surprising results. As might be suspected given the number of Toyota vehicles sold in SA and the fact that a Toyota brand is the best-selling vehicle in SA, the origin of a particular new car was indicated to be extremely important to these consumers. This response produced just over a $70 \%$ agreement rate on the survey while the selection of a Japanese vehicle was a close second with just over a $62 \%$ positive response rate. These results and the other related data outcomes are demonstrated in the following graphic:

Figure 1: Data Results from the SA New Car Market

\section{Data Results SA}

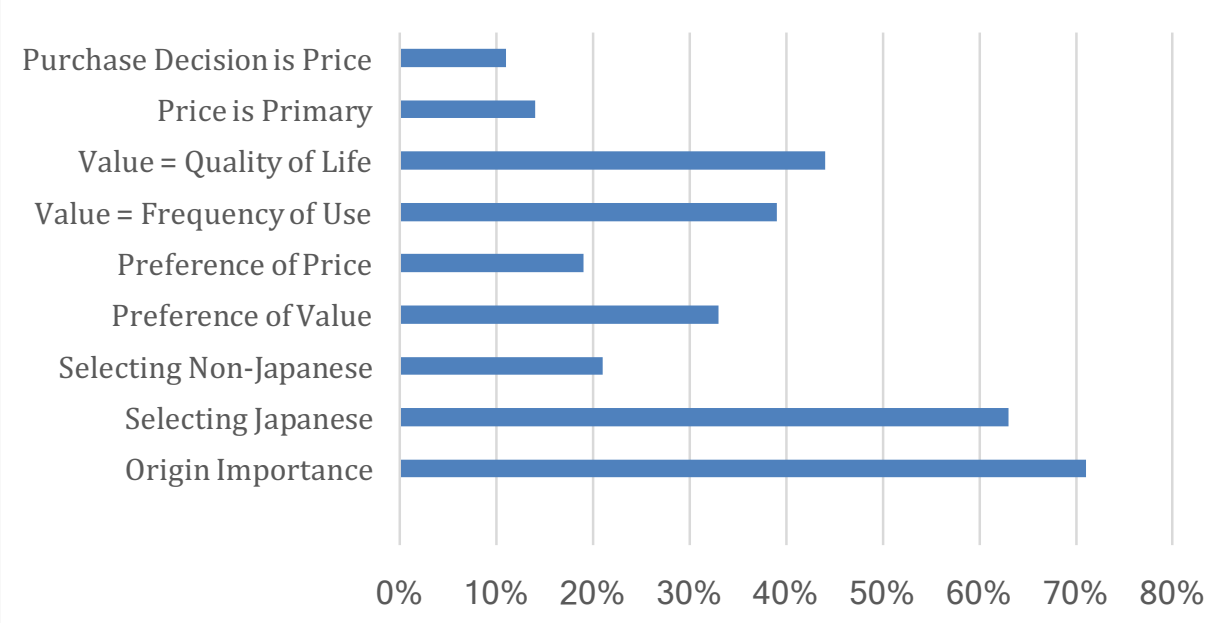

It is useful to note that the two factors involving value as a reason to purchase a new vehicle rank just behind the two previously cited outcomes. For instance, value as an indicator of quality of life received just more than $43 \%$ positive agreement while value a quotient of frequency of vehicle use came behind this at some $39 \%$ or so. Of course, the implication of these data is that the SA new car market is one that is indelibly associated with the concept of value.

This outcome is not particularly unexpected but it is a useful observation because the data confirms what has only been conjecture up to this point. There is a price related factor within the SA market on the part of some consumers to be sure. Yet, as the data and the existing research would indicate, price is a function of value but not vice-versa. It is evident from the existing research that the SA new car market will very soon surpass more than a million new car sales annually. Additionally, as the existing research found, Toyota which is perhaps the premiere Japanese brand globally, easily maintains a 31\% market share in the SA new car market. Hence, the SA new car market may be defined as one that focuses on value to be sure but it does have some significant segmentation in the new car market based on cost or price alone. This notion of a price consideration element in the SA new car market can be found in the Toyota Hilux outperforms most entire new car brands in the marketplace. 
In essence, despite the fact that the SA new car market is almost as diverse as the US market if one examines the overall number of different new car manufacturers represented in the marketplace, Japanese cars led by Toyota tend to be more venerated with respect to value. This is not to say that they are considered to be more of a social status symbol or other sociocultural icon but only that they are sought after by the majority of SA new car consumers. The data suggests that overall value is much more important to the SA new car consumer rather than price point. Of course, for some SA consumers, price point is not an option but rather a necessity and there are actually Japanese auto products that target these consumers. But, as the mean of the data indicates, even for price point oriented SA consumers, value is still the focus while price point is but one consideration within this overall framework of considerations.

In contrast to the SA data based on its domestic new car consumers, the US new car consumer adopts a somewhat different perspective. As the research material on the US new car market demonstrates, the market segmentation is much more vertically structured than in the SA new car market. Furthermore, there are some product categories that dominate in a way that the SA market does not experience such as pickups in the US market. The research from the US market demonstrates that pickups dominate the entire new car marketplace by $100 \%$ or more and this dominance of large vehicle sales is even larger if one includes large SUVs and crossovers. For instance, the data indicated that while there were 1.3 million passenger cars sold in the US during the 1st quarter of this year, there were 2.7 million light pickup trucks sold during the same period and another 1.8 million SUVs and crossovers. Thus, not only is the new car market in the US different based on its consumers but also on its preferences. Within these different product segments then it is price point that drives new vehicle consumer purchase decisions.

In this regard, while only some approximately $18 \%$ of the new car consumers indicated that the price drove their purchase decision, another 39\% said that it was a primary concern. Additionally, about 37\% indicated that they preferred some degree of price consciousness in making their decision to select a new car product. Combined, the price factor tends to dominate the entire rationale in selecting which new car product to purchase for US consumers but, increasingly, for the price it seems to be Japanese cars that offer the lowest prices while not sacrificing other elements. These data points are displayed on the figure below:

Figure 2: Data Results From the US New Car Market

Data Results US

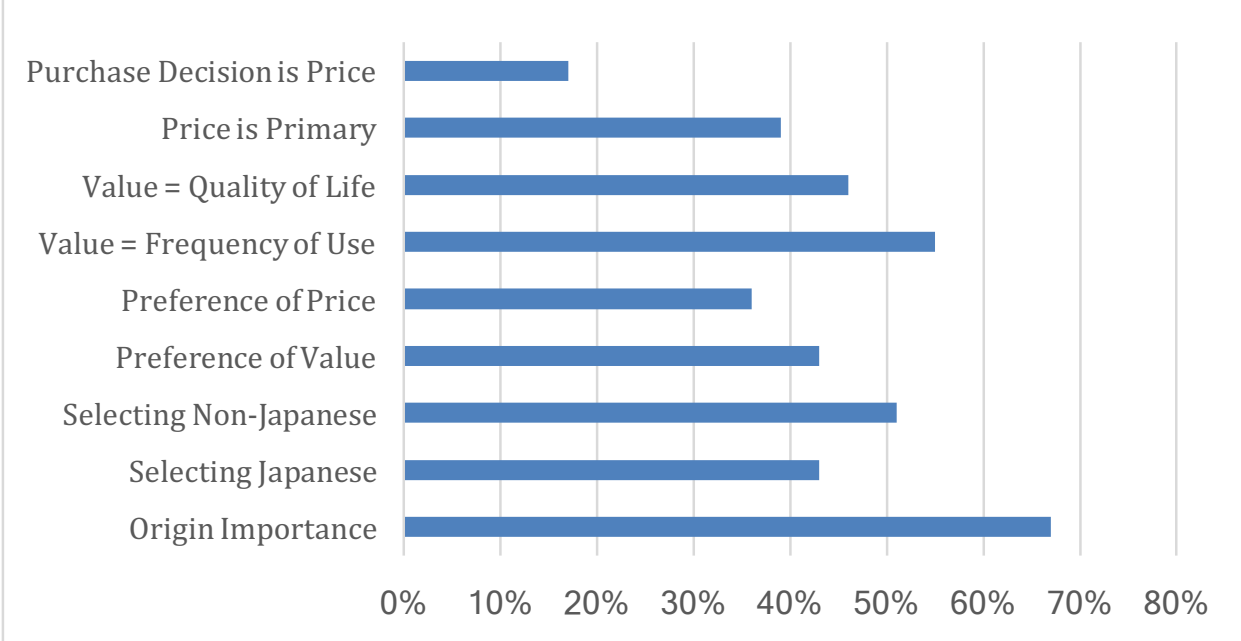


Thus, while the purchase decision price is visibly the lowest selected response from the survey for US new car consumers, when viewed collectively with the other price related statements, price is more of a concern for US consumers than overall value. This seems to be because quality is so high with the cars that populate the top 10 most sold cars list if one is to remove pickups from the equation. It just so happens, that for the price offered by Japanese cars, the quality is higher than it is for equivalent priced domestic and foreign non-Japanese cars.

\section{CONCLUSIONS AND RECOMMENDATIONS}

It is important to note that there are few if any absolutes in the realm of consumer preferences. This observation applies as much if not more to the realm of the new car market as it does to any other consumer product goods or CPG segment. It also applies easily to markets themselves regardless of country or region. That is, any market in any industry will always have some consumers that are purely focused on price and will always have some consumers that are purely focused on value or other product quality or feature (Wang, Chen \& Yang, 2015). This is why new car manufactures segment their products across the marketplace by various factors such as size, efficiency or features and so forth. For the marketing analyst working in any given industry, the challenge is determining where the majority of consumers tend to focus their purchase decision rationale. Once this is understood then marketing strategies can be developed to address these majority perspectives in the given marketplace.

There are several datapoints within the study that reinforce the notion that SA new car consumers tend to concentrate around the value quotient. This is the value quotient rather than the price quotient when making their new car purchase decision. For instance, while the referenced VAT increase of 5\% did have a depressive effect on new car purchases, it did not affect change on the percentage of Toyota's sold in the marketplace at all. SA new car consumers still bought Toyotas as well as other Japanese cars which implies that they purchase Japanese cars for reasons other than price. As mentioned, by no means is price never not a consideration except for the most wealthy consumers perhaps but the implication is that SA new car consumers appreciate other product features offered by Japanese cars that are not cancelled out by an unmanageable pricing scheme.

This finding is somewhat reversed in the US new car market. However, it should be observed that these two new car markets are vastly different in character. For one thing, the US new car market is defined by a completely different new car product segmentation scheme than that of the SA new car market. The US market, as noted, is dominated by certain product categories that are not fully replicated in the SA marketplace. Additionally, these product categories in the US market tend to be somewhat price insulated due to their unique features and product attributes-specifically pickup trucks. However, if one explores beyond the limited confines of this segmentation profile, the US new car consumer does tend to elevate pricepoint above that of overall value as a purchase decision rationale. This point is evident where the data demonstrated that through the 1st quarter of 2018, all passenger car categories sales percentages are down while those for pickups are demonstrably up. The US new car market is experiencing price inflation for new cars. Data indicates that the average price of a new car in the US marketplace has risen by as much as $4 \%$ across the board for most products and product categories in the new car market (Mitchell, 2018). A 4\% increase in the average price of a new car is hardly sustainable over the longterm and it is this fact that has ensured that US new car consumers are extremely price conscious when making a new car purchase decision. This is clearly exerting downward pressure on the purchase decision rationale for new car consumers in the US marketplace. 
In relation to the Saudi new car marketplace, the price of new cars is viewed somewhat differently than in the US new car market. Perhaps one of the most significant implications for this study and its results is that it offers evidence that the objectives of the Vision 2030 developed by the Crown Prince are working. The Vision 2030 objectives include those such as a greater integration and inclusion of all people within Saudi society, improved economic diversity, shifting the Kingdom's economy away from its dependence on petroleum based industries and finally preparing the economy and the Kingdom for life after petroleum. This kind of forward thinking and innovative governance model is rare for contemporary countries but the Kingdom is fortunate to have this type of leadership from its Crown Prince. In this regard, as one reviews the research and the findings from this study, it is apparent that new car consumers in SA are not only more diverse (inclusion of women) but also much more sophisticated in their expectations of new car products.

In previous eras, new car consumers in SA might have been focused primarily on status or limited factors such as performance or similar one-dimensional product attribute. However, with the elevation of Japanese cars in the Kingdom as the benchmark for new car purchases, new car consumers in SA are demonstrating how their tastes, preferences and understanding of the role that transportation plays in the Kingdom are critical economic factors. In the literature on the Vision 2030 goals and objectives, in the vision's grow and diversify the economy pillar, there are a series of level 1, 2 and 3 objectives that demonstrate how Japanese automobile acceptance reflects the vision's goals: Level 1-grow and diversify the economy, Level 2-further integrate Saudi economy regionally and globally and Level 3-improve local, regional and international connectivity of trade and transport networks (Strategic, 2018). It seems pretty clear that it is not only the popularity but also the basic acceptance of the Japanese automobile that demonstrates how effective the vision has been and will continue to be.

These factors all contribute to the recognition that efficiency, environmentalism and sustainability are important considerations in the purchase of a new car. Furthermore, another aspect of the Saudi Vision 2030 program that is designed to launch SA into the post-petroleum economy is the creation of the Public Investment Fund which will be funded largely through the initial public offering or IPO of the Kingdom's national oil company known as Aramco. The link between these elements of the Vision 2030 and its objectives with the findings of this study is that Japanese cars are recognized as being both functional and fuel efficient; both utilitarian and luxurious; and both costly and inexpensive-all based on the product segment one is shopping in. In earlier eras SA new car consumers would have been loathe to venture into some of these product categories. This is except for the fact that Japanese cars are in fact so popular in the Kingdom is evidence of the maturation of the domestic new car consumer in that market.

There are some similarities between the SA new car market and the US new car market. For instance, if the focus of the report concentrates purely on the element of preference for Asian vehicles (Japanese specifically) then both the SA new car market and the US new car market can be said to have a latent preference for Japanese produced vehicles. Yet, past this latent preference for Asia (Japanese) vehicles, many of the similarities between these two markets and these two new car consumer groups ends. The Saudi new car consumer is intent on getting the most features, highest quality and greatest marque for the price during the new car purchase transaction. This objective can only be referred to as the primacy of value as a purchase decision rationale. In contrast, the US new car consumer is obsessed with the idea of shopping around, price comparison and achieving dealer concessions during the purchase transaction (Jang, Prasad \& Ratchford, 2017). Therefore, pricepoint and price factors tend to 
drive the US new car consumers' purchase decision. Thus, SA new car consumers have a fairly high impression of Asian cars evidenced by the Hilife being the highest selling car in the Kingdom and this good impression of Asian cars is mirrored in the US market. Yet, SA new car consumers focus on the value proposition in the purchase transaction while US new car consumers focus on the price proposition.

\section{References}

Auto sales. (2018). The Wall Street Journal (online). Retrieved from: http://www.wsj.com/mdc/public/page/2_3022-autosales.html

Financing for women buying cars: 50\% increase in car sales in Saudi Arabia seen. (2017). Gulf News: Saudi Arabia (online). Retrieved from: https://gulfnews.com/news/ gulf/saudi-arabia/50-increase-in-car-sales-in-saudiarabia-seen-1.2097993

Jang, S., Prasad, A., \& Ratchford, B. T. (2017). Consumer Search of Multiple Information Sources and its Impact on Consumer Price Satisfaction. Journal of Interactive Marketing, 40, 24-40.

Mitchell, R. (2018). Average auto prices rise 4\%--An early sign of inflation. Los Angeles Times, 02(01), pp.06-07.

New car prices. (2018). KSA Hatla (online). Retrieved from: https://ksa.hatla2ee.com/en/car/all-prices

Omran, A. \& Campbell, P. (2018). Car groups in push to woo Saudi Arabia's new women drivers. Financial Times, 03(02), pp.07-11.

Saridakis, C., \& Baltas, G. (2016). Modeling price-related consequences of the brand origin cue: An empirical examination of the automobile market. Marketing Letters, 27(1), 77-87.

Saudi Arabia is the $15^{\text {th }}$ largest car market in the world. (2015). Motory Magazine, 03(24), pp.18-19.

Strategic objectives and vision realization programs: KSA vision 2030. Vision Realization Programs Overview (online). Retrieved from: http://vision2030.gov.sa/en

Tuttle-Hollingsworth, L. (2015). The quality perceptions of U.S. and foreign cars in the U.S. and Japan.

Developments in Marketing Science: Proceedings of the Academy of Marketing Science, 03(01), pp.225-230.

Uma, S. S., \& Ramanathan, H. N. (2016). Perception Mapping of Entry Level Passenger Cars-An Application of Multi Dimensional Scaling. International Journal of Marketing \& Business Communication, 5(3).

U.S. automotive industry—statistics \& facts. (2018). Statista (online). Retrieved from: https://www.statista.com/ topics/1721/us-automotive-industry/

Wang, M., Chen, W., Fu, Y., \& Yang, Y. (2015). Analyzing and Predicting Heterogeneous Customer Preferences in China's Auto Market Using Choice Modeling and Network Analysis. SAE International Journal of Materials and Manufacturing, 8(2015-01-0468), 668-677. 


\section{Appendix 1: Data Collection Tool}

\section{APPENDICES}

Respondent Nationality:
1. Saudi Arabia
2. United States

Respondent Gender
1. Male
2. Female

Respondent Age
1. 18-25
2. $26-35$
3. $36-50$
4. 51-60

\section{Questions/Responses}

$\lceil\quad$ Manufacturer of Origin Importance

$\lceil$ Selecting a Japanese Made Vehicle

$\Gamma$ Selecting a Non-Japanese Made Vehicle

$\ulcorner$ Preference of Overall Value (size, fuel efficiency, reliability)

$\Gamma$ Preference of Price (low cost, high cost)

Г Do not care

\section{Value/Price Statements}

$\Gamma$ Value is frequency of use \& utility

$\Gamma$ Value is associated with quality of life

$\lceil$ Price is my primary concern

$\ulcorner$ My purchase decision is based on price alone

\section{Appendix 2: Independency Test of Variances}

\begin{tabular}{|c|c|c|c|c|c|c|c|c|c|c|}
\hline & & \multicolumn{2}{|c|}{$\begin{array}{c}\text { Levene's Test } \\
\text { of Variances }\end{array}$} & \multicolumn{7}{|c|}{ T-Test } \\
\hline & & \multirow[b]{2}{*}{$\mathrm{F}$} & \multirow[b]{2}{*}{ Sig. } & \multirow[b]{2}{*}{$\mathrm{t}$} & \multirow[b]{2}{*}{ Df } & \multirow[b]{2}{*}{$\begin{array}{l}\text { Sig. }(2- \\
\text { tailed) }\end{array}$} & \multirow[b]{2}{*}{$\begin{array}{c}\text { Difference of } \\
\text { the Mean }\end{array}$} & \multirow[b]{2}{*}{$\begin{array}{l}\text { Standard } \\
\text { Error }\end{array}$} & \multicolumn{2}{|c|}{$\begin{array}{c}\text { 95\% Confidence } \\
\text { Interval }\end{array}$} \\
\hline & & & & & & & & & Lower & Upper \\
\hline $\begin{array}{l}\text { Assumption of } \\
\text { Equality in } \\
\text { Variance }\end{array}$ & $\begin{array}{l}\text { Assumption } \\
\text { of Inequality } \\
\text { in Variance }\end{array}$ & 3,374 & ,069 & $\begin{array}{l}-, 953 \\
-, 983\end{array}$ & $\begin{array}{r}93 \\
71,399\end{array}$ & $\begin{array}{l}343 \\
329\end{array}$ & $\begin{array}{l}-, 198 \\
-, 198\end{array}$ & $\begin{array}{l}, 208 \\
202\end{array}$ & $\begin{array}{l}-, 612 \\
-, 601\end{array}$ & $\begin{array}{l}215 \\
, 204\end{array}$ \\
\hline
\end{tabular}

